\title{
Energy decay and blow-up of solution for a Kirchhoff equation with dynamic boundary condition
}

\author{
Hongwei Zhang*, Changshun Hou and Qingying Hu
}

\section{"Correspondence:} whz661@163.com Department of Mathematics, Henan University of Technology, Lianhua Street, Zhengzhou, 450001, P.R. China

\begin{abstract}
The energy decay and blow-up of a solution for a Kirchhoff equation with dynamic boundary condition are considered. With the help of Nakao's inequality and a stable set, the energy decay of the solution is given. By the convexity inequality lemma and an unstable set, the sufficient condition of blow-up of the solution with negative and small positive initial energy are obtained, respectively.
\end{abstract}

\section{Introduction}

The aim of this article is to study the energy decay and blow-up of a solution of the following Kirchhoff-type equation with nonlinear dynamic boundary condition:

$$
\begin{aligned}
& u_{t t}+u_{t}+u_{x x x x}-M\left(\left\|u_{x}\right\|^{2}\right) u_{x x}=0, \quad 0<x<l, t>0, \\
& u(0, t)=u_{x x}(0, t), \quad t>0, \\
& u_{x x}(l, t)+u_{x}(l, t)=0, \quad t>0, \\
& u_{t t}(l, t)+u_{t}(l, t)-u_{x x x}(l, t)+M\left(\left\|u_{x}\right\|^{2}\right) u_{x}(l, t)=f(u(l, t)), \\
& u(x, 0)=u_{0}(x), \quad u_{t}(x, 0)=u_{1}(x), \quad 0<x<l,
\end{aligned}
$$

here $f(s)=|s|^{p-2} s, M(s)=1+s^{m}, p>2, m \geq 1$ are positive constants and $\left\|u_{x}\right\|^{2}=\int_{0}^{l} u_{x}^{2} d x$.

This problem is based on the equation

$$
u_{t t}+u_{x x x x}-\left(\alpha+\beta \int_{0}^{l} u_{x}^{2}(x, t) d x\right) u_{x x}=0
$$

which was proposed by Woinowsky-Krieger $[1,2]$ as a model for a vibrating beam with hinged ends, where $u(x, t)$ is the lateral displacement at the space coordinate $x$ and time $t$. Equation (6) was studied by many authors such as Dickey [3], Ball Rivera [4], Tucsnak [5], Kouemou Patchen [6], Aassila [7], Oliveira and Lima [8]; Wu and Tsai [9] considered the following beam equation:

$$
u_{t t}+\alpha \Delta^{2} u-M\left(\|\nabla u\|^{2}\right) \Delta u+g\left(u_{t}\right)=f(u), \quad \text { in } \Omega \subset R^{n} .
$$


They obtained the existence and uniqueness, as well as decay estimates, of global solutions and blow-up of solutions for the initial boundary value problem of equation (7) through various approaches and assumptive conditions. Feireisl [10] and Fitzgibbon et al. [11] showed the existence of a global attractor and an inertial manifold of equation (6) with damping $u_{t}$. Ma [12] studied the existence and decay rates for the solution of equation (6) with nonlinear boundary conditions

$$
u_{x x x}(l, t)-M\left(\int_{0}^{l} u_{x}^{2}(x, t) d x\right) u_{x}(l, t)=f(u(l, t))+g\left(u_{t}(l, t)\right) .
$$

Pazoto and Menzala [13] were concerned with equation (6) with rotational inertia term $-u_{x x t t}$ and nonlinear boundary condition (8). Santos et al. [14] established the existence and exponential decay of the Kirchhoff systems with nonlocal boundary condition. Guedda and Labani [15] gave the sufficient condition of the blow-up of the solution to equation (7) with $g\left(u_{t}\right)=u_{t}$ and dynamic boundary condition. As the related problem, we mention the following:

$$
u_{t t}-M\left(\|\nabla u\|^{2}\right) \Delta u+Q\left(t, x, u, u_{t}\right)+f(x, u)=0,
$$

we refer the reader to [16-19].

When $f=0$ and $M(s)=\beta+k s$, problem (1)-(5) comes from the reference [20-22]. In this case, the model describes the weakly damped vibrations of an extensible beam whose ends are a fixed distance apart if one end is hinged while a load is attached to the other end [21]. One can find many references on problem (1)-(5) with $M=0$ and $f=0$, for example, Littman and Markus [23], Andrews et al. [24], Conrad and Morgul [25], Rao [26].

Dalsen [21,22] showed the exponential stability of problem (1)-(5) with $m=1$ and $f=0$. Park et al. [27] discussed the existence of the solution of the Kirchhoff equation with dynamic boundary conditions and boundary differential inclusion. Doronin and Larkin [28] and Gerbi and Said-Houari [29] were concerned with the wave equation with dynamic boundary conditions. Recently, Autuori and Pucci [30] studied the global nonexistence of solutions of the p-Kirchhoff system with dynamic boundary condition.

In this paper, we use the idea of references [31] to get the energy decay and blow-up of the solution for problem (1)-(5). We construct a stable set and an unstable set, which is similar to [32]. By the help of Nakao's inequality, combining it with the stable set, we get the decay estimate. We find that the set of initial data such that the solution of problem (1)-(5) is decay, is smaller than the potential well in [32]. The blow-up properties of the solution of problem (1)-(5) with small positive initial energy and negative initial energy are obtained by using the convexity lemma [33]. These results are different from the results in $[29,30]$.

\section{Assumptions and preliminaries}

In this section, we give some preliminaries which are used throughout this work.

We use the standard space $L^{p}[0, l]$ and the Sobolev space $H_{0}^{1}(0, l), H^{2}(0, l)$ with their usual scalar products and norms. Especially, $\|\cdot\|_{p}$ denotes the norm of $L^{p}[0, l]$ and $\|\cdot\|$ the norms $L^{2}[0, l]$.

We denote $V=\left\{u \mid u \in H^{2}(0, l), u(0)=u_{x x}(0)=0\right\}$. 


\section{Lemma 2.1}

(1) If $u \in H_{0}^{1}$, then

$$
|u(l)|^{2} \leq\left\|u_{x}\right\|^{2}, \quad\|u\|^{2} \leq C_{0}\left\|u_{x}\right\|^{2} ;
$$

(2) If $u \in V$ and $u_{x x}(l)+u_{x}(l)=0$, then

$$
\|u\|^{2} \leq C_{1}\left(\left\|u_{x x}\right\|^{2}+u_{x}^{2}(l, t)\right) \leq C_{1}\left(\left\|u_{x x}\right\|^{2}+u_{x x}^{2}(l, t)\right) .
$$

Proof Since $u(0)=0$, we have

$$
|u(x)|^{2}=\left|u(0)+\int_{0}^{x} u_{x}(s) d s\right|^{2} \leq\left|\int_{0}^{l} u_{x}^{2}(s) d s\right|
$$

Take $x=l$, we get the first inequality of (9). Integrating the above inequality over $[0, l]$, we get the second part of (9). From the following equation

$$
u_{x}(x)=u_{x}(l)-\int_{x}^{l} u_{x x}(s) d s=-u_{x x}(l)-\int_{x}^{l} u_{x x}(s) d s
$$

and the Cauchy inequality, we can get the result of (10) with the help of (9).

Lemma 2.2 [34] Let $\phi(t)$ be a non-increasing and nonnegative function on $[0, \infty)$ such that

$$
\sup _{s \in[t, t+1]} \phi(s) \leq C(\phi(t)-\phi(t+1)), \quad t>0,
$$

then

$$
\phi(t) \leq C e^{-\omega t},
$$

where $C, \omega$ are positive constants depending on $\phi(0)$ and other known qualities.

Lemma 2.3 [33] Suppose that a positive, twice-differentiable function $H(t)$ satisfies on $t \geq 0$ the inequality

$$
H^{\prime \prime}(t) H(t)-(\beta+1)\left(H^{\prime}(t)\right)^{2} \geq 0,
$$

where $\beta>0$, then there is a $t_{1}<t_{2}=\frac{H(0)}{\beta H^{\prime}(0)}$ such that $H(t) \rightarrow \infty$ as $t \rightarrow t_{1}$.

A solution $u$ of problem (1)-(5) means that there exists $T>0$ such that

$$
u \in C([0, T], V) \cap C^{1}\left([0, T], H_{0}^{1}(0, l) \cap H^{2}(0, l)\right), \quad u_{t t} \in C\left(0, T ; L^{2}[0, l]\right),
$$

and it satisfies the following identity

$$
\begin{aligned}
& \int_{0}^{t}\left\{\left(u_{t t}, \varphi\right)-M\left(\left\|u_{x}\right\|^{2}\right)\left(u_{x}, \varphi_{x}\right)+\left(u_{x x}, \varphi_{x x}\right)\right. \\
& \quad+\left(u_{t}, \varphi\right)+u_{t t}(l, \tau) \varphi(l, \tau)+u_{t}(l, \tau) \varphi(l, \tau)-f(u(l, \tau) \varphi(l, \tau)\} d \tau=0
\end{aligned}
$$

for all $\varphi \in C((0, T), V) \cap C^{1}\left(0, T ; L^{2}(0, l)\right)$. 
In this paper, we always assume that a local solution exists for problem (1)-(5). In order to study the energy decay or the blow-up phenomenon of the solution of problem (1)-(5), we define the energy of the solution $u$ of problem (1)-(5) by

$$
\begin{aligned}
E(t)= & E(u(t)) \\
= & \frac{1}{2}\left\|u_{t}\right\|^{2}+\frac{1}{2}\left\|u_{x x}\right\|^{2}+\frac{1}{2}\left\|u_{x}\right\|^{2}+\frac{k}{2(m+1)}\left\|u_{x}\right\|^{2(m+1)}+\frac{1}{2}\left|u_{t}(l, t)\right|^{2} \\
& +\frac{1}{2}\left|u_{x x}(l, t)\right|^{2}-\frac{1}{p}|u(l, t)|^{p} .
\end{aligned}
$$

The initial energy is defined by

$$
\begin{aligned}
E(0)= & \frac{1}{2}\left\|u_{1}\right\|^{2}+\frac{1}{2}\left\|u_{0 x x}\right\|^{2}+\frac{1}{2}\left\|u_{0 x}\right\|^{2}+\frac{k}{2(m+1)}\left\|u_{0 x}\right\|^{2(m+1)}+\frac{1}{2}\left|u_{t}(l, t)\right|^{2} \\
& +\frac{1}{2}\left|u_{0 x x}(l)\right|^{2}-\frac{1}{p}|u(l, t)|^{p} .
\end{aligned}
$$

Then, after some simple computation, we have

$$
\frac{d}{d t} E(t)=-\left\|u_{t}\right\|^{2}-\left|u_{t}(l, t)\right|^{2}<0
$$

That is to say, $E(t)$ is a non-increasing function on $[0, \infty)$. Moreover, we have

$$
E(t)+\int_{0}^{t}\left[\left\|u_{t}\right\|^{2}+\left|u_{t}(l, s)\right|^{2}\right] d s=E(0) .
$$

We denote

$$
\begin{aligned}
& B_{1}^{-1}=\inf _{u \in V} \frac{\left\|u_{x x}\right\|}{|u(l)|}, \\
& \lambda_{0}=B_{1}^{-\frac{p}{p-2}}, \quad E_{0}=\left(\frac{1}{2}-\frac{1}{p}\right) \lambda_{0}^{2} .
\end{aligned}
$$

We can now define a stable set and an unstable set [31]

$$
\Sigma_{0}=\left\{(\lambda, E) \in R^{2} \mid 0<\lambda<\lambda_{0}, 0<E \leq E_{0}\right\}, \quad \Sigma^{e}=\left\{(\lambda, E) \in R^{2} \mid \lambda>\lambda_{0}, 0<E<E_{0}\right\} .
$$

\section{Energy decay of the solution}

In order to get the energy decay of the solution, we introduce the following set:

$$
\Sigma_{1}=\left\{(\lambda, E) \in R^{2} \mid 0<\lambda<\lambda_{1}, 0<E<E_{1}\right\}
$$

where $\lambda_{1}=\left(p B_{1}^{p}\right)^{-\frac{1}{p-2}}, E_{1}=\left(\frac{1}{2}-\frac{1}{p}\right) \lambda_{1}^{2}$. Obviously, $\Sigma_{1} \subset \Sigma_{0}$.

Adapting the idea of Vitillaro [35], we have the following lemma.

Lemma 3.1 Suppose that $u$ is the solution of (1)-(5), $u_{0} \in V, u_{1} \in L^{2}$ and $\left(\left\|u_{0 x x}\right\|, E(0)\right) \in$ $\Sigma_{1}$, then $\left(\left\|u_{x x}(t)\right\|, E(t)\right) \in \Sigma_{1}$, for $t \geq 0$. 
Lemma 3.2 Under the condition of Lemma 3.1 and $p>2$, then, for $t \geq 0$,

$$
\begin{aligned}
& \left\|u_{x x}\right\|^{2} \geq 2|u(l, t)|^{p}, \\
& E(t) \geq \frac{p-1}{2 p}\left\|u_{x x}\right\|^{2} \geq \frac{p-1}{p}|u(l, t)|^{p}, \\
& E(t) \geq C_{3}\left(\left\|u_{x x}\right\|^{2}+\left|u_{x x}(l, t)\right|^{2}\right) .
\end{aligned}
$$

Proof By (14) and (18), we have

$$
\begin{aligned}
E(t) & \geq \frac{1}{2}\left\|u_{x x}\right\|^{2}-\frac{1}{p}|u(l, t)|^{p} \geq \frac{1}{2}\left\|u_{x x}\right\|^{2}-|u(l, t)|^{p} \\
& \geq \frac{1}{2}\left\|u_{x x}\right\|^{2}-B_{1}^{p}\left\|u_{x x}\right\|^{p}=G\left(\left\|u_{x x}\right\|\right),
\end{aligned}
$$

where $G(\lambda)=\frac{1}{2} \lambda^{2}-B_{1}^{p} \lambda^{p}$. Note that $G(\lambda)$ has the maximum at $\lambda_{1}=\left(p B_{1}^{p}\right)^{-\frac{1}{p-2}}$ and the maximum value $G\left(\lambda_{1}\right)=E_{1}$. We see that $G(\lambda)$ is increasing in $\left(0, \lambda_{1}\right)$, decreasing in $\left(\lambda_{1}, \infty\right)$ and $G(\lambda) \rightarrow 0$ as $\lambda \rightarrow \infty$. Since $\left\|u_{x x}\right\|<\lambda_{1}, E(0)<E_{1}$, then $\left\|u_{x x}\right\|<\lambda_{1}$ for any $t \geq 0$, so $G\left(\left\|u_{x x}\right\|\right) \geq 0$.

By (24), we have

$$
\left\|u_{x x}\right\|^{2}-|u(l, t)|^{p}=\frac{1}{2}\left\|u_{x x}\right\|^{2}+\left(\frac{1}{2}\left\|u_{x x}\right\|^{2}-|u(l, t)|^{p}\right) \geq \frac{1}{2}\left\|u_{x x}\right\|^{2}+G\left(\left\|u_{x x}\right\|\right),
$$

then (21) holds since $G\left(\left\|u_{x x}\right\|\right)>0$. Furthermore, we have

$$
E(t) \geq \frac{1}{2}\left\|u_{x x}\right\|^{2}-\frac{1}{p}|u(l, t)|^{p} \geq \frac{p-1}{2 p}\left\|u_{x x}\right\|^{2} .
$$

So (22) holds. Similar to (25), the above equality becomes

$$
E(t) \geq \frac{1}{2}\left\|u_{x x}\right\|^{2}+\frac{1}{2}\left|u_{x x}(l, t)\right|^{2}-\frac{1}{p}|u(l, t)|^{p} \geq \frac{p-1}{2 p}\left\|u_{x x}\right\|^{2}+\frac{1}{2}\left|u_{x x}(l, t)\right|^{2},
$$

so (23) holds.

Theorem 3.3 Let $p>2$, $\left(\left\|u_{0 x x}\right\|, E(0)\right) \in \Sigma_{1}$, and $u$ be the solution of problem (1)-(5), then there exist two positive constants $l$ and $\theta$ independent of $t$ such that

$$
E(t) \leq l e^{-\theta t}, \quad t \geq 0 .
$$

Proof From (16), we have

$$
\int_{t}^{t+1}\left[\left\|u_{t}(s)\right\|^{2}+\left|u_{t}(l, s)\right|^{2}\right] d s=E(t)-E(t+1)
$$

Now, for the above estimate and the mean value theorem, we choose $t_{1} \in\left[t, t+\frac{1}{4}\right]$ and $t_{2} \in\left[t+\frac{3}{4}, t+1\right]$ such that, for $i=1,2$,

$$
\left\|u_{t}\left(t_{i}\right)\right\| \leq\left(\int_{t}^{t+1}\left\|u_{t}(s)\right\|^{2} d s\right)^{\frac{1}{2}} \leq C(E(t)-E(t+1))^{\frac{1}{2}},
$$




$$
\left|u\left(l, t_{i}\right)\right| \leq\left(\int_{t}^{t+1}|u(l, s)|^{2} d s\right)^{\frac{1}{2}} \leq C(E(t)-E(t+1))^{\frac{1}{2}}
$$

Multiplying equation (1) by $u$ and integrating over $[0, l] \times\left[t_{1}, t_{2}\right]$, by the boundary conditions (2) and (3), we have

$$
\begin{aligned}
& \int_{t_{1}}^{t_{2}}\left[\left\|u_{x x}\right\|^{2}+\left\|u_{x}\right\|^{2}+k\left\|u_{x}\right\|^{2(m+1)}+\left|u_{x x}(l, s)\right|^{2}-|u(l, s)|^{p}\right] d s \\
& =\int_{t_{1}}^{t_{2}}\left[\left(u_{t t}, u\right)+u_{t}(l, s) u(l, s)+\left(u_{t}, u\right)+u_{t t}(l, s) u(l, s)\right] d s \\
& \leq \sum_{i=1}^{2}\left[\left\|u_{t}\left(t_{i}\right)\right\|\left\|u\left(t_{i}\right)\right\|+\left|u_{t}\left(l, t_{i}\right) \| u\left(l, t_{i}\right)\right|\right]+\int_{t_{1}}^{t_{2}}\left[\left\|u_{t}\right\|^{2}+u_{t}^{2}(l, s)\right] d s \\
& \quad+\int_{t_{1}}^{t_{2}}\left[\left\|u_{t}\right\|\|u\|+\left|u_{t}(l, s) \| u(l, s)\right|\right] d s .
\end{aligned}
$$

Now, we estimate the terms of the right-hand side of (29). By (10), (23), (27) and the Young inequality, we have

$$
\begin{aligned}
I_{1} & =\sum_{i=1}^{2}\left\|u_{t}\left(t_{i}\right)\right\|\left\|u\left(t_{i}\right)\right\| \leq C(E(t)-E(t+1))^{\frac{1}{2}} \sum_{i=1}^{2}\left\|u\left(t_{i}\right)\right\| \\
& \leq \varepsilon E(t)+C(\varepsilon)(E(t)-E(t+1)) .
\end{aligned}
$$

It follows from (9), (10), (23), (28) and the Young inequality that

$$
\begin{aligned}
I_{2} & =\sum_{i=1}^{2}\left|u_{t}\left(l, t_{i}\right)\right|\left|u\left(l, t_{i}\right)\right| \leq C(E(t)-E(t+1))^{\frac{1}{2}} \sum_{i=1}^{2}\left|u\left(l, t_{i}\right)\right| \\
& \leq \varepsilon E(t)+C(\varepsilon)(E(t)-E(t+1)) .
\end{aligned}
$$

From (26), we get

$$
I_{3}=\int_{t_{1}}^{t_{2}}\left[\left\|u_{t}\right\|^{2}+u_{t}^{2}(l, s)\right] d s \leq C(E(t)-E(t+1)) .
$$

From the Young inequality, (10), (23), (26) and from the fact that $E(t)$ is non-increasing, we arrive at

$$
I_{4}=\int_{t_{1}}^{t_{2}}\left\|u_{t}\right\|\|u\| d s \leq \varepsilon E(t)+C(\varepsilon)(E(t)-E(t+1)) .
$$

By the Young inequality, (9), (10), (23), (26) and the fact that $E(t)$ is non-increasing, we obtain

$$
I_{5}=\int_{t_{1}}^{t_{2}}|u(l, s)|\left|u_{t}(l, s)\right| d s \leq \varepsilon E(t)+C(\varepsilon)(E(t)-E(t+1)) .
$$


Substituting (30)-(34) into (29), we get the estimate

$$
\begin{aligned}
& \int_{t_{1}}^{t_{2}}\left[\left\|u_{x x}\right\|^{2}+\left\|u_{x}\right\|^{2}+k\left\|u_{x}\right\|^{2(m+1)}+\left|u_{x x}(l, s)\right|^{2}-|u(l, s)|^{p}\right] d s \\
& \quad \leq \varepsilon E(t)+C(\varepsilon)(E(t)-E(t+1)) .
\end{aligned}
$$

On the other hand, it follows from (22) that

$$
\begin{aligned}
E(t)= & \frac{1}{2}\left(\left\|u_{x x}\right\|^{2}-|u(l, t)|^{p}\right)+\frac{1}{2}\left\|u_{x}\right\|^{2}+\frac{k}{2(m+1)}\left\|u_{x}\right\|^{2(m+1)}+\frac{1}{2}\left\|u_{t}\right\|^{2} \\
& +\frac{1}{2}\left|u_{t}(l, t)\right|^{2}+\frac{1}{2}\left|u_{x x}(l, t)\right|^{2}+\frac{p-2}{2 p}|u(l, t)|^{p} \\
\leq & \frac{1}{2}\left(\left\|u_{x x}\right\|^{2}-|u(l, t)|^{p}\right)+\frac{1}{2}\left\|u_{x}\right\|^{2}+\frac{k}{2(m+1)}\left\|u_{x}\right\|^{2(m+1)}+\frac{1}{2}\left\|u_{t}\right\|^{2} \\
& +\frac{1}{2}\left|u_{t}(l, t)\right|^{2}+\frac{1}{2}\left|u_{x x}(l, t)\right|^{2}+\frac{p-2}{2(p-1)} E(t) .
\end{aligned}
$$

Then we have

$$
\begin{aligned}
\frac{p}{2(p-1)} E(t) \leq & \frac{1}{2}\left[\left\|u_{x x}\right\|^{2}+\left\|u_{x}\right\|^{2}+k\left\|u_{x}\right\|^{2(m+1)}+\left|u_{x x}(l, t)\right|^{2}-|u(l, t)|^{p}\right] \\
& +\frac{1}{2}\left\|u_{t}\right\|^{2}+\frac{1}{2}\left|u_{t}(l, t)\right|^{2} .
\end{aligned}
$$

Therefore, by (37), (35) and (26), we arrive at

$$
\begin{aligned}
\int_{t_{1}}^{t_{2}} E(s) d s \leq & C \int_{t_{1}}^{t_{2}}\left[\left\|u_{x x}\right\|^{2}+\left\|u_{x}\right\|^{2}+k\left\|u_{x}\right\|^{2(m+1)}\right. \\
& \left.+\left|u_{x x}(l, s)\right|^{2}-|u(l, s)|^{p}\right] d s+C \int_{t_{1}}^{t_{2}}\left(\left\|u_{t}\right\|^{2}+\left|u_{t}(l, s)\right|^{2}\right) d s \\
\leq & \varepsilon_{1} E(t)+C\left(\varepsilon_{1}\right)(E(t)-E(t+1)) \\
\leq & \varepsilon_{1} \sup _{s \in[t, t+1]} E(s)+C\left(\varepsilon_{1}\right)(E(t)-E(t+1)) .
\end{aligned}
$$

Since $E(t)$ is non-increasing, we choose $t_{3} \in\left[t_{1}, t_{2}\right]$ such that

$$
E\left(t_{3}\right) \leq C \int_{t_{1}}^{t_{2}} E(s) d s .
$$

Then, using (26), $t_{3}<t+1$, and the fact that $E(t)$ is non-increasing, we have

$$
\begin{aligned}
E(t) & =E(t+1)+\int_{t}^{t+1}\left[\left\|u_{t}(s)\right\|^{2}+\left|u_{t}(l, s)\right|^{2}\right] d s \leq E\left(t_{3}\right)+\int_{t}^{t+1}\left[\left\|u_{t}(s)\right\|^{2}+\left|u_{t}(l, s)\right|^{2}\right] d s \\
& \leq C \int_{t_{1}}^{t_{2}} E(s) d s+\int_{t}^{t+1}\left[\left\|u_{t}(s)\right\|^{2}+\left|u_{t}(l, s)\right|^{2}\right] d s .
\end{aligned}
$$

Since $E(t)$ is non-increasing, combining this with (40), (38) and (26), we have

$$
\sup _{s \in[t, t+1]} E(s) \leq \varepsilon_{1} \sup _{s \in[t, t+1]} E(s)+C\left(\varepsilon_{1}\right)(E(t)-E(t+1)) .
$$


Choosing $\varepsilon_{1}$ sufficiently small, (41) leads to

$$
\sup _{s \in[t, t+1]} E(s) \leq C(E(t)-E(t+1))
$$

then, applying Lemma 2.2, we obtain the energy decay.

\section{Blow-up property}

In this section, we show that the solution of problem (1)-(5) blows up in finite time if $E(0)<E_{0}$.

Lemma 4.1 Suppose $p>2$, $\left(\left\|u_{0 x x}\right\|, E(0)\right) \in \Sigma^{e}$, then

$$
\left\|u_{x x}\right\| \geq \lambda_{0}, \quad 0<E(t)<E_{0}, \quad t \geq 0 .
$$

Proof Since $E(t)$ is non-increasing, and $0<E(0)<E_{0}$, then $0<E(t)<E_{0}$ for $t \geq 0$. Similar to the proof of Lemma 3.2, we have

$$
E(t) \geq \frac{1}{2}\left\|u_{x x}\right\|^{2}-\frac{1}{p}|u(l, t)|^{p} \geq \frac{1}{2}\left\|u_{x x}\right\|^{2}-\frac{1}{p} B_{1}^{p}\left\|u_{x x}\right\|^{p}=g\left(\left\|u_{x x}\right\|\right),
$$

where $g(\lambda)=\frac{1}{2} \lambda^{2}-\frac{1}{p} B_{1}^{p} \lambda^{p}$. Note that $g(\lambda)$ has the maximum at $\lambda_{0}=B_{1}^{-\frac{2 p}{p-2}}$ and the maximum value is $g\left(\lambda_{0}\right)=E_{0}$. It is easy to verify that $g(\lambda)$ is increasing for $0<\lambda<\lambda_{0}$, decreasing in $\lambda>\lambda_{0}$ and $g(\lambda) \rightarrow-\infty$ as $\lambda \rightarrow+\infty$. Therefore, since $E(0)<E_{0}$, there exists $\lambda_{2}>\lambda_{0}$ such that $g\left(\lambda_{2}\right)>E(0)$. By (44), we have $g\left(\left\|u_{0 x x}\right\|\right) \leq E(0)=g\left(\lambda_{2}\right)$, which implies $\left\|u_{0 x x}\right\| \geq \lambda_{2}$. We claim that

$$
\left\|u_{x x}(t)\right\| \geq \lambda_{2}, \quad t>0
$$

Otherwise, we suppose that $\left\|u_{x x}\left(t_{0}\right)\right\|<\lambda_{2}$ for some $t_{0}>0$ and by the continuity of $\left\|u_{x x}\right\|$, we can choose $t_{0}$ such that $\left\|u_{x x}\left(t_{0}\right)\right\|<\lambda_{0}$.

Again the use of (44) leads to

$$
E\left(t_{0}\right) \geq g\left(\left\|u_{x x}\left(t_{0}\right)\right\|\right)>g\left(\lambda_{2}\right)=E(0) .
$$

This is impossible since $E(t) \leq E(0)$ for all $t \geq 0$. Hence, (45) holds. Furthermore, (43) is established since $\lambda_{2}>\lambda_{0}$.

Theorem 4.2 Suppose that $u$ is the local solution of problem (1)-(5), $p>2(m+1), E(0)<0$, then the solution $u$ blows up at some finite time.

Proof Let

$$
\begin{aligned}
F(t)= & \|u\|^{2}+u^{2}(l, t)+\int_{0}^{t}\left[\|u(s)\|^{2}+u^{2}(l, s)\right] d s \\
& +\left(T_{0}-t\right)\left(u_{0}^{2}(l)+u_{0 x x}^{2}(l)\right)+\beta\left(t+t_{0}\right)^{2}
\end{aligned}
$$


where $t_{0}, T_{0}, \beta$ are positive constants which will be fixed later (see Levine [33]). Then one finds

$$
\begin{aligned}
F^{\prime}(t)= & 2\left(u, u_{t}\right)+2 u(l, t) u_{t}(l, t)+2 \int_{0}^{t}\left[\left(u(s), u_{s}(s)\right)+u(l, s) u_{s}(l, s)\right] d s+2 \beta\left(t+t_{0}\right) . \\
F^{\prime \prime}(t)= & 2\left\|u_{t}\right\|^{2}+2 u_{t}^{2}(l, t)+2\left(u, u_{t}\right)+2 u(l, t) u_{t}(l, t)+2 \beta+2\left(u, u_{t t}\right)+2 u(l, t) u_{t t}(l, t) \\
= & 2\left\|u_{t}\right\|^{2}+2 u_{t}^{2}(l, t)-2\left\|u_{x x}\right\|^{2}-2 u_{x x}^{2}(l, t)-2\left\|u_{x}\right\|^{2} \\
& -2 k\left\|u_{x}\right\|^{2(m+1)}+2 \beta+2|u(l, t)|^{p} .
\end{aligned}
$$

By (17) and (14), we have

$$
\begin{aligned}
F^{\prime \prime}(t)= & F^{\prime \prime}(t)+2 p(E(t)-E(0))+2 p \int_{0}^{t}\left[\left\|u_{t}\right\|^{2}+\left|u_{t}(l, s)\right|^{2}\right] d s \\
= & (p+2)\left[\left\|u_{t}\right\|^{2}+u_{t}^{2}(l, t)+\int_{0}^{t}\left[\left\|u_{t}(s)\right\|^{2}+\left|u_{t}(l, s)\right|^{2}\right] d s+\beta\right] \\
& +(p-2)\left[\left\|u_{x x}\right\|^{2}+u_{x x}^{2}(l, t)+\left\|u_{x}\right\|^{2}+k\left\|u_{x}\right\|^{2(m+1)}\right]-p(\beta+2 E(0)) \\
& +(p-2) \int_{0}^{t}\left[\left\|u_{t}\right\|^{2}+\left|u_{t}(l, s)\right|^{2}\right] d s .
\end{aligned}
$$

Taking $0<\beta<-2 E(0)$ and noticing $p>2$, we get

$$
F^{\prime \prime}(t) \geq(p+2)\left[\left\|u_{t}\right\|^{2}+u_{t}^{2}(l, t)+\int_{0}^{t}\left[\left\|u_{t}(s)\right\|^{2}+u_{t}^{2}(l, s)\right] d s+\beta\right] .
$$

By the Hölder inequality, we have

$$
\begin{aligned}
{\left[F^{\prime}(t)\right]^{2} \leq } & 4\left[\|u\|^{2}\left\|u_{t}\right\|^{2}+u(l, t) u_{t}(l, t)+\left(\int_{0}^{t}\|u\|^{2} d s\right)^{\frac{1}{2}}\left(\int_{0}^{t}\left\|u_{t}\right\|^{2} d s\right)^{\frac{1}{2}}\right. \\
& \left.+\left(\int_{0}^{t} u^{2}(l, s) d s\right)^{\frac{1}{2}}\left(\int_{0}^{t} u_{t}^{2}(l, s) d s\right)^{\frac{1}{2}}+\beta\left(t+t_{0}\right)^{2}\right]
\end{aligned}
$$

Denote

$$
\begin{array}{llll}
A_{1}=\|u\|^{2}, & A_{2}=\int_{0}^{t} u^{2}(l, s) d s, & A_{3}=\int_{0}^{t}\|u\|^{2} d s, & A_{4}=u^{2}(l, t), \\
B_{1}=\left\|u_{t}\right\|^{2}, & B_{2}=\int_{0}^{t} u_{t}^{2}(l, s) d s, & B_{3}=\int_{0}^{t}\left\|u_{t}\right\|^{2} d s, & B_{4}=u_{t}^{2}(l, t) .
\end{array}
$$

Then, by (48), (51), (52) and the Cauchy-Schwarz inequality, we arrive at

$$
\begin{aligned}
& F(t) F^{\prime \prime}(t)-\frac{p+2}{4}\left[F^{\prime}(t)\right]^{2} \\
& \quad \geq(p+2)\left[A_{1}+A_{2}+A_{3}+A_{4}+\beta\left(t+t_{0}\right)^{2}\right]\left[B_{1}+B_{2}+B_{3}+B_{4}+\beta\right] \\
& \quad-(p+2)\left[A_{1}^{\frac{1}{2}} B_{1}^{\frac{1}{2}}+A_{2}^{\frac{1}{2}} B_{2}^{\frac{1}{2}}+A_{3}^{\frac{1}{2}} B_{3}^{\frac{1}{2}}+A_{4}^{\frac{1}{2}} B_{4}^{\frac{1}{2}}+\beta\left(t+t_{0}\right)^{2}\right]^{2} \geq 0 .
\end{aligned}
$$


Take $t_{0}$ sufficiently large such that

$$
F^{\prime}(0)=2\left(u_{0}, u_{1}\right)+2 u_{0}(l) u_{1}(l)+2 \beta t_{0} .
$$

Noticing $F(0)>0$, by Lemma 2.3, we get the result.

Theorem 4.3 Suppose that $u(x, t)$ is the local solution of problem (1)-(5), $p>2(m+1)$, and that either of the following conditions is satisfied:

(i) $E(0)=0$ and $\left(u_{0}, u_{1}\right)+u_{0}(l) u_{1}(l)>0$;

(ii) $0<E(0)<E_{0}$ and $\left\|u_{0 x x}\right\|>\lambda_{0}\left(\right.$ or $\left.\left(\left\|u_{0 x x}\right\|, E(0)\right) \in \Sigma^{e}\right)$;

then the solution $u$ blows up at some finite time.

Proof (i) For $E(0)=0$, similar to the proof of Theorem 4.2, we take $\beta=0$ in (51), then (53) holds. Since $F(0)>0, F^{\prime}(0)=2\left(u_{0}, u_{1}\right)+2 u_{0}(l) u_{1}(l)>0$, then the result holds by Lemma 2.3 .

(ii) For the case of $0<E(0)<E_{0}$, from (48), (49), (50) and (14), we get

$$
\begin{aligned}
F^{\prime \prime}(t)= & 2\left[\left\|u_{t}\right\|^{2}+u_{t}^{2}(l, t)-\left\|u_{x x}\right\|^{2}-u_{x x}^{2}(l, t)-\left\|u_{x}\right\|^{2}-k\left\|u_{x}\right\|^{2(m+1)}+\beta\right] \\
& +p\left[\left\|u_{t}\right\|^{2}+u_{t}^{2}(l, t)+\left\|u_{x x}\right\|^{2}+u_{x x}^{2}(l, t)+\left\|u_{x}\right\|^{2}+k\left\|u_{x}\right\|^{2(m+1)}-2 E(t)\right] \\
= & (p+2)\left[\left\|u_{t}\right\|^{2}+u_{t}^{2}(l, t)\right]+(p-2)\left[\left\|u_{x x}\right\|^{2}+u_{x x}^{2}(l, t)+\left\|u_{x}\right\|^{2}\right. \\
& \left.+\left(\frac{p}{m+1}-2\right) k\left\|u_{x}\right\|^{2(m+1)}\right]+2 \beta-2 p E(t) .
\end{aligned}
$$

By Lemma 4.1,

$$
(p-2)\left\|u_{x x}\right\|^{2} \geq(p-2) \lambda_{0}^{2}=2 p E_{0}
$$

Combining (55) with (56), $E(0)<E_{0}$ and (17), we get

$$
\begin{aligned}
F^{\prime \prime}(t) \geq & (p+2)\left[\left\|u_{t}\right\|^{2}+u_{t}^{2}(l, t)\right]+(p-2)\left\|u_{x x}\right\|^{2}+2 \beta-2 p E(t) \\
\geq & (p+2)\left[\left\|u_{t}\right\|^{2}+u_{t}^{2}(l, t)\right]+2 p\left(E_{0}-E(0)\right)+2 \beta \\
& +2 p \int_{0}^{t}\left[\left\|u_{t}\right\|^{2}+u_{t}^{2}(l, s)\right] d s .
\end{aligned}
$$

Take $\beta=2\left(E_{0}-E(0)\right)>0$, then $2 p\left(E_{0}-E(0)\right)+2 \beta=(p+2) \beta>0$, since $p>2$ and $2 p>p+2$, then (57) can be rewritten

$$
F^{\prime \prime}(t) \geq(p+2)\left[\left\|u_{t}\right\|^{2}+u_{t}^{2}(l, t)+\beta+\int_{0}^{t}\left[\left\|u_{t}\right\|^{2}+u_{t}^{2}(l, s) d s\right]\right.
$$

The remainder of the proof is the same as the proof of Theorem 4.2. 


\section{Authors' contributions}

The authors declare that the study was realized in collaboration with the same responsibility. All authors read and approved the final manuscript.

\section{Acknowledgements}

We thank the referees for their valuable suggestions which helped us improve the paper so much. This work was supported by the National Natural Science Foundation of China (11171311) and the Key Science Foundation of Henan University of Technology (09XZD009).

\section{Received: 16 November 2012 Accepted: 27 June 2013 Published: 12 July 2013}

\section{References}

1. Woinowsky-Krieger, S: The effect of axial force on the vibration of hinged bars. J. Appl. Mech. 17, 35-36 (1980)

2. Ball, J: Stability theory for an extensible beam. J. Differ. Equ. 14, 58-66 (1973)

3. Dickey, KW: Infinite systems of nonlinear oscillation equations with linear damping. SIAM J. Appl. Math. 7, 208-214 (1970)

4. Munoz Rivera, JE: Global stabilization and regularizing properties on a class of nonlinear evolution equation. J. Differ. Equ. 128, 103-124 (1996)

5. Tucsnak, M: Semi-internal stabilization for a nonlinear Euler-Bernoulli equation. Math. Methods Appl. Sci. 9, 897-907 (1996)

6. Patcheu, SK: On a global solution and asymptotic behavior for the generalized damped extensible beam equation. J. Differ. Equ. 135(2), 123-138 (1997)

7. Aassila, M: Decay estimate for a quasi-linear wave equation of Kirchhoff type. Adv. Math. Sci. Appl. 9(1), 371-381 (1999)

8. Oliveira, ML, Lima, OA: Exponential decay of the solutions of the beams system. Nonlinear Anal. 42, 1271-1291 (2000)

9. $\mathrm{Wu}, \mathrm{ST}$, Tsai, LY: Existence and nonexistence of global solutions for a nonlinear wave equation. Taiwan. J. Math. 13B(6), 2069-2091 (2009)

10. Feireisl, F: Exponential attractor for non-autonomous systems long-time behavior of vibrating beams. Math. Methods Appl. Sci. 15, 287-297 (1992)

11. Fitzgibbon, WE, Parrott, M, You, YC: Global dynamics of coupled systems modelling non-planar beam motion. In: Ferreyra, G, Goldstein, GK, Neubrander, F (eds.) Evolution Equation. Lectures Notes in Pure and Appl. Math. Ins., vol. 168, pp. 187-189. Marcel Dekker, New York (1995)

12. Ma, TF: Boundary stabilization for a nonlinear beam on elastic bearings. Math. Methods Appl. Sci. 24, 583-594 (2001)

13. Pazoto, AF, Menzala, GP: Uniform rates of decay of a nonlinear beam with boundary dissipation. Report of LNCC/CNPq (Brazil), no 34/97, August 1997.

14. Santos, ML, Rocha, MPC, Pereira, DC: Solvability for a nonlinear coupled system of Kirchhoff type for the beam equations with nonlocal boundary conditions. Electron. J. Qual. Theory Differ. Equ. 6, 1-28 (2005)

15. Guedda, M, Labani, H: Nonexistence of global solutions to a class of nonlinear wave equations with dynamic boundary conditions. Bull. Belg. Math. Sci. 9, 39-46 (2002)

16. Autuori, G, Pucci, P, Salvaton, MC: Asymptotic stability for nonlinear Kirchhoff systems. Nonlinear Anal., Real World Appl. 10, 889-909 (2009)

17. Tawiguchi, T: Existence and asymptotic behavior of solutions to weakly damped wave equations of Kirchhoff type with nonlinear damping and source terms. J. Math. Anal. Appl. 36, 566-578 (2010)

18. Nakao, M: An attractor for a nonlinear dissipative wave equation of Kirchhoff type. J. Math. Anal. Appl. 353, 652-659 (2009)

19. Li, FC: Global existence and blow-up of solutions for higher-order Kirchhoff-type equation with nonlinear dissipation. Appl. Math. Lett. 17, 1409-1414 (2004)

20. Grobbelaar-van Dalsen, M: On the initial-boundary-value problem for the extensible beam with attached load. Math. Methods Appl. Sci. 19, 943-957 (1996)

21. Grobbelaar-van Dalsen, M, Van der Merwe, A: Boundary stabilization for the extensible beam with attached load. Math. Models Methods Appl. Sci. 9, 379-394 (1999)

22. Grobbelaar-van Dalsen, M: On the solvability of the boundary-value problem for the elastic beam with attached load. Math. Models Methods Appl. Sci. 4, 89-105 (1994)

23. Littman, W, Markus, L: Stabilization of a hybrid system of elasticity by feedback boundary damping. Ann. Math. Pures Appl. 152, 281-330 (1988)

24. Andrews, KT, Kuttler, KL, Shillor, M: Second order evolution equation with dynamic boundary conditions. J. Math. Anal. Appl. 197, 781-795 (1996)

25. Conrad, F, Morgul, O: On the stabilization of a flexible beam with a tip mass. SIAM J. Control Optim. 36, 1962-1966 (1998)

26. Rao, BP: Uniform stabilization of a hybrid system of elasticity. SIAM J. Control Optim. 33, 440-454 (1995)

27. Park, JY, Park, SH: Solution for a hyperbolic system with boundary differential inclusion and nonlinear second-order boundary damping. Electron. J. Differ. Equ. 80, 1-7 (2003)

28. Doronin, GG, Larkin, NA: Global solvability for the quasi-linear damped wave equation with nonlinear second-order boundary condition. Nonlinear Anal. 8, 1119-1134 (2002)

29. Gerbi, S, Said-Houari, B: Local existence and exponential growth for a semi-linear damped wave equation with dynamical boundary conditions. Adv. Differ. Equ. 13, 1051-1060 (2008)

30. Autuori, G, Pucci, P: Kirchhoff system with dynamic boundary conditions. Nonlinear Anal. 73, 1952-1965 (2010)

31. Todorova, G: Stable and unstable sets for the Cauchy problem for a nonlinear wave equation with nonlinear damping and source terms. J. Math. Anal. Appl. 239, 213-226 (1999)

32. Payne, L, Sattinger, D: Saddle points and instability on nonlinear hyperbolic equations. Isr. J. Math. 22, 273-303 (1973)

33. Levine, HA: Some additional remarks on the nonexistence of global solutions to nonlinear wave equations. SIAM J. Math. Anal. 5, 138-146 (1974) 
34. Nakao, M, Ono, K: Global existence to the Cauchy problem of the semi-linear evolution equations with a nonlinear dissipation. Funkc. Ekvacioj 38, 417-431 (1995)

35. Vitillaro, E: A potential well method for the wave equation with nonlinear source and boundary damping terms. Glasg. Math. J. 44, 375-395 (2002)

doi:10.1186/1687-2770-2013-166

Cite this article as: Zhang et al.: Energy decay and blow-up of solution for a Kirchhoff equation with dynamic

boundary condition. Boundary Value Problems 2013 2013:166.

Submit your manuscript to a SpringerOpen ${ }^{\circ}$ journal and benefit from:

- Convenient online submission

- Rigorous peer review

Immediate publication on acceptance

Open access: articles freely available online

- High visibility within the field

- Retaining the copyright to your article

Submit your next manuscript at $>$ springeropen.com 